\title{
TRAJETÓRIA HISTÓRICA E CARACTERÍSTICAS DA PRODUÇÁO CIENTÍFICA DA REVISTA BAIANA DE ENFERMAGEM
}

\author{
HISTORICAL DEVELOPMENT AND CHARACTERISTICS OF THE \\ SCIENTIFIC PRODUCTION OF THE BAHIA JOURNAL OF NURSING
}

\author{
TRAYECTORIA HISTÓRICA Y CARACTERÍSTICAS DE LA \\ PRODUCCIÓN CIENTÍFICA DE LA REVISTA BAIANA DE \\ ENFERMAGEM
}

\author{
Gilberto Tadeu Reis Da Silva* \\ Núbia Lino De Oliveira** \\ Elaine Kelly Nery Carneiro-Zunino*** \\ Juliana Maciel Machado Paiva**** \\ Virginia Ramos Dos Santos Souza***** \\ LUCIANA BARIZON LUCHESI******
}

\begin{abstract}
RESUMO
Objetivo: Descrever a trajetória histórica e apresentar as características da produção científica da Revista Baiana de Enfermagem no período de 1981 a 2017. Material e Método: Estudo descritivo analítico; utiliza a pesquisa histórica e técnicas bibliométricas para consubstanciar e ilustrar os processos implicados na trajetória do período estudado. Os dados foram obtidos no acervo do Núcleo de Memória da Escola de Enfermagem da Universidade Federal da Bahia, no acervo físico e eletrônico da revista. Resultados: Construção de uma linha do tempo da RBE, com a primeira edição publicada em 1981, na comemoração dos 35 anos da Escola de Enfermagem da Universidade Federal da Bahia, apontava para o momento histórico da Escola, e a concretizaçáo do sonho de divulgar a produção científica da enfermagem. No período estudado, 671 artigos foram publicados, com crescimento linear no número de registros $\left(\mathrm{R}^{2}=0,5472\right)$. Os documentos eram artigos originais $(64,38 \% ; \mathrm{n}=$ 432), entre outras tipologias de documentos, quanto à metodologia a maior expressividade foi a abordagem qualitativa. O periódico publicou, expressivamente, artigos da região nordeste, denotando o seu caráter regional e seu principal eixo temático a enfermagem em diversas perspectivas. Conclusão: A revista se constituiu em um grande veículo divulgador da produçáo científica da enfermagem nacionalmente, e principalmente para região nordeste, e já com avanços em bases de dados internacionais. Apresenta crescimento linear do número de artigos
\end{abstract}

*Doutor, Professor Titular-Livre, Universidade Federal da Bahia, Salvador, Brasil. Email: gilberto.tadeu@ufba.br. Autor correspondente.

**Mestre, Enfermeira, Secretaria Municipal de Saúde, Salvador, Brasil. Email: nubialinooliveira@gmail.com

***Mestre, Enfermeira, Universidade Federal da Bahia, Salvador, Brasil. Email: lanenery@hotmail.com

****Enfermeira, Universidade Federal da Bahia, Salvador, Brasil. Email: julianammp@yahoo.com

*****Mestre, Professora, Universidade Federal da Bahia, Salvador, Brasil. Email: virginia.ramos@ufba.br.

******Doutora, Professora, Universidade de São Paulo, Ribeirão Preto, Brasil. Email: luchesi@eerp.usp.br 
publicados que coaduna com o amadurecimento da gestão editorial e com as alteraçóes com o cenário social, político e econômicos do Brasil.

Palavras-chave: Enfermagem; Pesquisa em Enfermagem; Publicaçôes Periódicas; História da Enfermagem; Bibliometria.

\begin{abstract}
Objective: To describe the historical development and present the characteristics of the scientific production of the Revista Baiana de Enfermagem from 1981 to 2017. Material and Method: Descriptive analytical study uses historical research and bibliometric technique to validate and show the processes involved during the study period. The data were obtained from the records of the Nursing College of the Universidade Federal da Bahia, and from the journal's physical and electronic collection. Results: Journal timeline elaboration, with the first edition published in 1981 during the 35th anniversary commemoration of the School of Nursing of the Federal University of Bahia, which historical moment reflected the school's desire to contribute to the advancement of scientific production of nursing. During the period, 671 articles were published, showing linear growth in the number of records $\left(R^{2}=0.5472\right)$. The documents corresponded to original articles $(64.38 \% ; n=432)$ among other types, and presented a mainly qualitative approach. The journal published, primarily, articles from the northeastern region of Brazil, indicating its regional character and its main thematic area of nursing from several perspectives. Conclusion: The journal has been an important instrument for scientific dissemination of national nursing, especially for the northeastern region, and has advanced in the indexation within international databases. The linear growth in the number of published articles is an evidence of the editorial management progress and reflects the social, political and economic changes in Brazil.
\end{abstract}

Key words: Nursing; Nursing research; Journals; Nursing history; Bibliometrics.

\title{
RESUMEN
}

Objetivo: Describir la trayectoria histórica y presentar las características de la producción científica de la Revista Baiana de Enfermagem en el período 1981 a 2017. Material y Método: Estudio descriptivo y analítico que utiliza la investigación histórica y técnicas bibliométricas para corroborar e ilustrar los procesos involucrados en la trayectoria del período estudiado. Los datos se encontraron en la colección del Centro de la Memoria de la Escuela de Enfermería de la Universidade Federal da Bahia de Brasil y en la colección física y electrónica de la revista. Resultados: Construcción de una línea de tiempo de la RBE, con la primera edición publicada en 1981 en la conmemoración del 35ªniversario de la Escuela, cuyo momento histórico marchaba hacia el cumplimiento del deseo de contribuir con la difusión de la producción científica de enfermería. Durante el período de estudio se publicaron 671 artículos, con un crecimiento lineal en el número de registros $\left(\mathrm{R}^{2}=\right.$ 0,5472). Los documentos eran artículos originales $(64,38 \% ; n=432)$, entre otras tipologías de documentos, y un enfoque mayormente cualitativo. La revista publicó, predominantemente, artículos de la región noreste, denotando el carácter regional; su eje temático principal es la enfermería en varias perspectivas. Conclusión: La revista ha sido un gran instrumento para la difusión científica de la enfermería nacional, especialmente de la región noreste y ha avanzado en la indexación en bases de datos internacionales. El crecimiento lineal del número de artículos publicados corresponde a la maduración de la gestión editorial y los cambios en el escenario social, político y económico en Brasil.

Palabras clave: Enfermería; Investigación en enfermería; Publicaciones periódicas; Historia de enfermería; Bibliometría. 


\section{INTRODUÇÃO}

A Revista Baiana de Enfermagem (RBE) évinculada à Escola de Enfermagem da Universidade Federal da Bahia (EEUFBA), e foi constituída no momento em que a EEUFBA completava 35 anos de existência. Inicialmente com objetivo de ser veículo de divulgação da produção científica do primeiro programa de pós-graduação em enfermagem do nordeste (1979) e da escola, que logo se consolidou como referência regional e nacional para divulgação das pesquisas. Extrapolando seu objetivo inicial, mantém o desafio de acompanhar a evolução da cultura editorial nacional e se potencializar como um veículo internacional.

A RBE historicamente marca o cenário nacional, sendo o $7^{\circ}$ periódico oficial lançado e editado na área de Enfermagem no país. Os periódicos que circulavam anteriormente, por ordem crescente, e seus respectivos anos de lançamento foram: Revista Brasileira de Enfermagem (1932), Revista da Escola de Enfermagem da Universidade de São Paulo (USP) (1967), Enfoque (catálogo USP a consta 1972 NLM Catalog da PUB Med, indica 1974), Revista Enfermagem em novas dimensóes (1975), Revista Gaúcha de Enfermagem (1976), Revista Paulista de Enfermagem (1981).

O primeiro periódico de Enfermagem no Brasil, intitulado Anaes de Enfermagem (1932), sob responsabilidade da Associação Nacional de Enfermeiras Diplomadas Brasileiras, atual Associação Brasileira de Enfermagem, foi fruto de influência americana durante o $1^{\circ}$ Congresso Quadrienal do Conselho Internacional de Enfermeiras (ICN), no Canadá, com participação da entidade Brasileira, representada por Edith M. Fraenkel. A ideologia americana pressupunha que o desenvolvimento profissional de uma categoria dependia principalmente de uma associaçáo e uma revista. Inspirada neste ideal temos a revista brasileira, atualmente, denominada Revista Brasileira de Enfermagem-REBEn ${ }^{(1)}$.

A RBE tem sua história pautada na busca pela qualidade e no potencial técnico-científico regional, constituído da tradição e das conquistas acadêmicas para toda região nordeste na área de Enfermagem, como o primeiro curso de mestrado em 1979 e, o primeiro curso de doutorado em 2005, na Bahia.

Desde primeiro número da revista, a equipe contou com a assessoria da Editora da Universidade
Federal da Bahia (EDUFBA), que contribuiu para a profissionalização dos processos editoriais da $\mathrm{RBE}$. A participação da EDUFBA apoiou a busca para atender às exigências de qualidade, divulgação e socialização da produção científica nos campos da saúde e da enfermagem, de forma a obter crescente reconhecimento nacional e internacional $\mathrm{da}$ comunidade acadêmica e profissionais de saúde ${ }^{(2)}$.

A apresentação da história da RBE fornece subsídios para compreensão de parte da história da produção científica da Enfermagem no Brasil ${ }^{(3)}$. Dado que a RBE, ao longo dos seus mais de 35 anos, possibilitou a publicação de resultados de pesquisa produzidos no Brasil e no exterior.

Assim, transcorrido esse período (1981 a 2017) caracterizado por modificações em cenários sociais, econômicos, políticos, tecnológicos, educacionais e entre outros, busca-se responder aos seguintes questionamentos: Qual o percurso histórico da RBE? Quais as características da produção científica desta revista? Desse modo, objetiva-se neste estudo descrever a trajetória histórica e apresentar características da produção científica da RBE no período de 1981 a 2017.

O cunho histórico permite entender em profundidade os fenômenos ocorridos por meio da busca documental, vez que permite a reconstrução da contextualização histórica. A história se faz com uma infinidade de papéis cotidianos, como administrativo, regulatórios e legais, além de fontes não governamentais e dados bibliométricos, visando ampliar a pesquisa histórica com uma abordagem prática e analítica, que habilita que a informação registrada possa quantificar a produção científica ${ }^{(4)}$. A adoção de técnicas bibliométricas permite caracterizar e analisar as publicaçôes científicas, possibilitando análises desde autoria, periódicos, instituições, temáticas e relaçóes intrínsecas e extrínsecas entre os anteriormente citados.

\section{MATERIAL E MÉTODO}

Tipo de estudo: Este é um artigo descritivo analítico, que utiliza a pesquisa histórica e técnicas bibliométricas para consubstanciar e ilustrar os processos implicados na trajetória da revista entre o período de 1981 a 2017.

Coleta de dados: Neste estudo, os procedimentos/ 
técnicas bibliométricas aplicadas foram destinadas a subsidiar a análise dos aspectos históricos da revista, além de visibilizar a produção científica da RBE quantitativamente, possibilitando conhecer as temáticas pesquisadas, a curva da produção científica por ano, os tipos de documentos, as instituições afiliadas, metodologias além dos descritores mais utilizados. Os locais de pesquisa foram o acervo do Núcleo de Memória da Escola de Enfermagem da Universidade Federal da Bahia (NUMEE), o acervo físico e eletrônico da RBE. A coleta de dados dos documentos impressos ocorreu no período de janeiro a junho de 2017 e a dos documentos eletrônicos até dezembro de 2017. Para a pesquisa histórica, as fontes de coleta de dados foram: os documentos relativos a implantação da revista (atas, portarias, regimento, normas de publicação, fluxo editorial, formulário de assinatura da revista), o livro do cinquentenário da Escola de Enfermagem da Universidade Federal da Bahia; além de editoriais, pois esses apresentam um posicionamento político e funcionam como marcadores de processos históricos e políticos.

Análise de dados: Para selecionar os documentos que versassem a respeito da RBE, procedeu-se a leitura do acervo, após a seleção, foi realizada a leitura exploratória e aprofundada dos documentos, nos quais foi possível extrair tanto registros históricos e marcos temporais relacionados ao processo de implantação, constituição e consolidação da revista. Visando consubstanciar os marcadores históricos identificados, optamos pela aplicação de técnicas bibliométricas. Nessa direção, elegemos a análise agregada dos números impressos e os eletrônicos da RBE. Para tanto se extraiu dados dos artigos originais e revisóes, pois estes passaram por avaliação por pares, garantindo o caráter científico dos mesmos. As variáveis adotadas para essa pesquisa foram: quantidade de artigos, edição, ano, título, tipo de estudo, tipo de análise, método de análise, descritores/palavras-chave, instituição de vínculo $\mathrm{e}$ estado dos autores.

No atinente às variáveis bibliométricas, extraídas dos artigos originais e de revisão, essas foram organizadas através de planilha eletrônica. Em seguida, procedemos a análises univariados, bivariados e projeção relativa à tendência da publicação de artigos no período em questão, utilizando Statistical Package for the Social Sciences
(SPSS) e o Microsoft Excel. Para apresentar uma visão global das temáticas publicadas pelo periódico, construiu-se uma nuvem de palavras extraídas dos descritores/palavras-chaves definidos pelos autores. A nuvem de palavras é um recurso que organiza-as, em várias cores e tamanhos, com base no número de ocorrências. Esse procedimento permite a apresentação gráfica das temáticas indicadas pelos autores nos artigos publicados. Para operacionalização dessa análise, os procedimentos adotados foram: 1) listar todos os termos indicados pelos autores; 2) organizar em ordem alfabética; 3) realizar normalização e correção ortográfica (quando necessário); e 4) importar para o software ATLAS TI ${ }^{(5)}$.

Aspectos éticos: A proposta considera a Lei de acesso à informação, relativa a documentos públicos sem a indicação de confidencialidade (atinentes aos documentos da Escola de Enfermagem/RBE) e, no tocante aos artigos, a cessão dos direitos autorais pelos autores, a um periódico de acesso aberto e gratuito a sociedade, dispensando autorização de Comitê de Ética em Pesquisa com seres humanos.

\section{RESULTADOS}

Trajetória histórica da RBE: O corpus documental que versavam sobre a revista foi composto por 63 fontes: memorial de cinquentenário da Escola de Enfermagem da Universidade Federal da Bahia, 44 editoriais, 8 atas, 5 portarias, 1 regimento da RBE, 1 arquivo de normas de publicação, 1 fluxograma editorial, 1 formulário para assinatura da revista e uma contracapa, cujo os dados foram extraídos e organizados em uma linha do tempo da revista (Figura 1).

O primeiro número e volume (número especial) foram compostos por um editorial e sete artigos com autoria de docentes e discentes da EEUFBA. O editorial assinado pela diretora -Maria do Rosário Barbosa Nogueira - apontava para o momento histórico da Escola, destacando a realização dos primeiros concursos para professor titular, além da concretização do desejo de divulgar a produção científica de interesse da classe de enfermeiras ${ }^{(2)}$.

Para composição do primeiro número da RBE, a comissão provisória de editoração foi formada pelas docentes: Stella Maria Santos de Sena, Anaita 
de Oliveira Costa, Stella Maria Pereira Fernandes de Barros e Sônia Maria Passos da Silva Pinto; e contou com importante apoio do reitor da UFBA, disponibilizando verbas e suporte técnico da gráfica Universitária $^{(2)}$.

Em 1985 iniciou a publicação regular e semestral, mantida até o ano seguinte. Em 1986 a RBE foi indexada na Base de Dados de Enfermagem (BDENF) e na Literatura Latino-Americana e do Caribe em Ciências da Saúde (LILACS). O Regimento Interno foi publicado em 1987, com registro em cartório, conforme os procedimentos legais da época.

Desse modo, em 1987, publicou-se um volume da revista contendo os dois números anuais, e, devido à dificuldade financeira, não houve publicação em 1988, sendo esta agregada aos volumes dos anos de 1989 e 1990.

Em 1992 a RBE passou por novo processo de avaliação, seguido por reestruturação de aspectos organizacionais e gerenciais. A retomada da editoração regular possibilitou a promoção do intercâmbio com outros periódicos nacionais como a Revista da Escola de Enfermagem da Universidade de São Paulo, Revista Gaúcha de Enfermagem e Revista Paulista de Enfermagem. Essas relações colaboraram para a ampliação do número de artigos do acervo bibliográfico da EEUFBA, mesmo com a crise financeira do país e da própria $\operatorname{EEUFBA}^{(6)}$.

As dificuldades enfrentadas para consolidação do periódico, como o fechamento do número da revista, ao número restrito de submissóes recebidas e às restriçóes financeiras foram registradas em ata $\mathrm{da}$ reunião extraordinária do Conselho Departamental da EEUFBA em 8 de maio de $1995^{(7)}$.

A RBE foi vinculada ao Programa de PósGraduação em Enfermagem da UFBA em 1997, o qual assumiu a responsabilidade para manutenção da estrutura e adequação do espaço físico de funcionamento da revista (ARQUIVO RBE). O Regimento Interno e o formulário de avaliação dos trabalhos foram reformulados, seguidos do recadastramento e da atualização do corpo de consultores ad hoc, em 1998. Nesse processo, várias comissóes editoriais nortearam e aprimoraram a estrutura organizacional da RBE.

Além disso, a RBE contribui para consolidação do projeto acadêmico, pós-graduação e pesquisa. Os poucos recursos obtidos posteriormente, por meio de financiamento junto ao $\mathrm{CNPq}$, programas de apoio a Publicaçóes científicas e ao Banco do Brasil, possibilitou manter a periodicidade de suas publicações $^{(7)}$.

Figura 1. Linha do tempo da Revista Baiana de Enfermagem. Salvador - Bahia 2018.

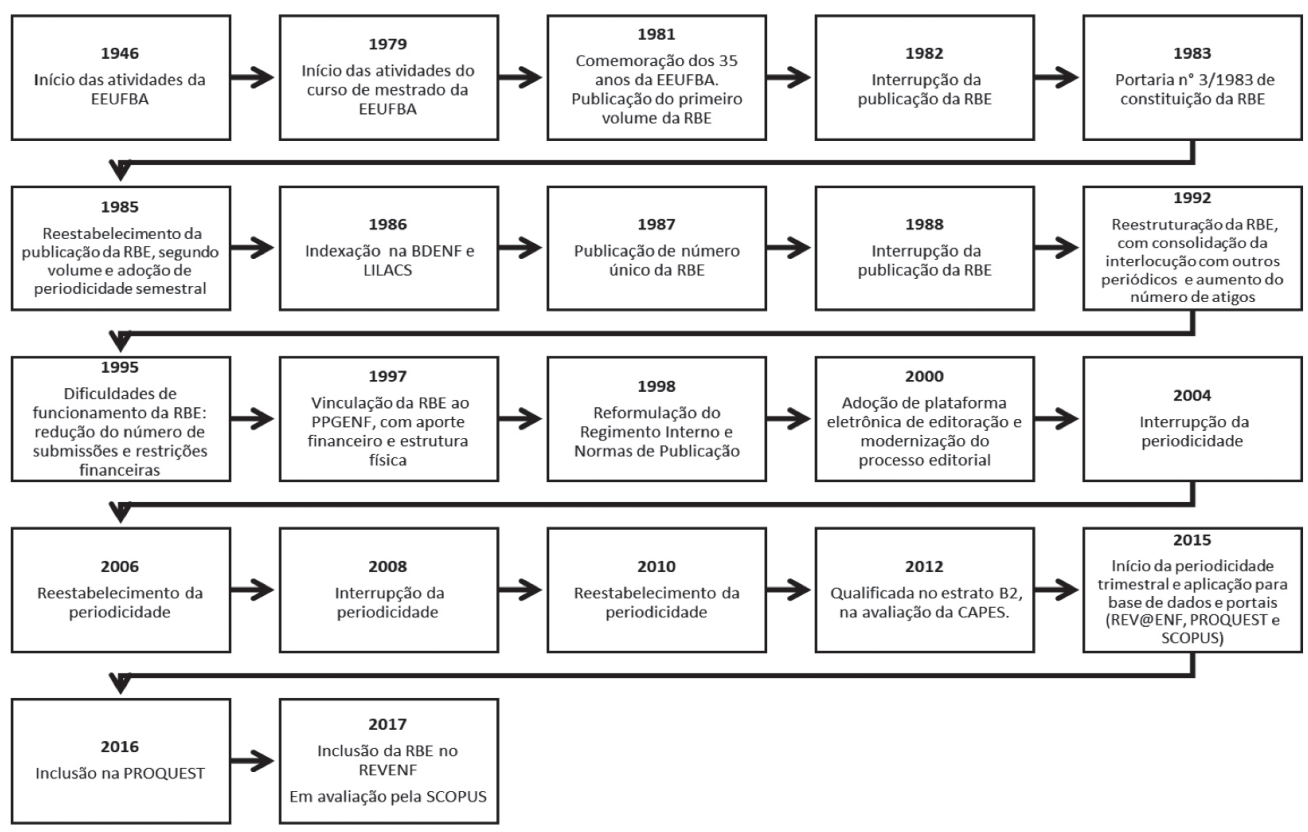

Fonte: Elaboração das autoras 
O uso de plataforma eletrônica para editoração teve início em 2000. Na primeira década do século XXI a RBE promoveu um processo de modernização intenso e aprimoramento da gestão editorial, demarcado pela alocação do periódico na plataforma do Sistema Eletrônico de Editoração de Revistas - o Portal SEER, que adota a metodologia Open Journal Systems (OJS), plataforma eletrônica para gestão de processos editoriais.

A partir desse período, a equipe da $\mathrm{RBE}$ continuou engajada no aprimoramento dos processos editoriais e manutenção da periodicidade, que evoluiu de quadrimestral para trimestral em 2015, seguida de fluxo contínuo em 2018. Em 2015 a RBE solicitou indexação em diversas bases de dados e portais com representatividade nacional e internacional, logrando êxito nos Portais REVENF, PROQUEST e SCOPUS. Caracterizaçáo dos 35 anos de atividades editoriais da RBE: $O$ quantitativo de artigos publicados pela $\mathrm{RBE}$ no período de 1981 a 2017 foram 44 fascículos, totalizando 671 publicações (Figura 2).

ARBE, no período estudado, publicou em média $23,1(\sigma=15,6)$ artigos por ano. Nas duas primeiras décadas do periódico, registra-se irregularidade no quantitativo de publicaçóes, compatíveis com a trajetória histórica da revista.
Em simultaneidade aos processos apresentados na trajetória histórica, as diversas equipes editoriais da RBE mantiveram a qualidade e o rigor no processo editorial, acompanhando as culturas editoriais e amadurecimento da enfermagem científica brasileira. Nessa direção, identificamos que artigos originais vêm se constituindo o cerne do periódico, como é definido pelas boas práticas editoriais (Tabela 1). Os artigos também foram categorizados quanto à metodologia adotada e descrita pelos autores (Tabela 2).

Alguns autores apontaram aspectos relativos ao aporte teórico-metodológico como Fenomenologia e Representaçóes Sociais. Outros aspectos relativos às metodologias foram identificados como: análise descritiva exploratória, descritiva analítica, estudos de caso, qualitativo-exploratório e exploratóriodescritivo.

O estudo identificou 1441 autores nos 671 artigos publicados pela revista, com média de 2,15 autores por artigo. $\mathrm{O}$ estado de residência e regiáo do país foram identificados e sumarizados na Tabela 3 .

O registro de local de procedência de 39 autores não foi identificado, todavia, desse total, 4 autores são vinculados a 3 instituiçóes do exterior: Universita Degli Studi Luigi Bocconi, Escola Superior de Enfermagem de Lisboa e Universidade Católica Portuguesa.

Figura 2. Distribuição do quantitativo de documentos, segundo o ano e linha de tendência de crescimento linear e logarítmico da RBE - 1981 a 2017. Salvador - Bahia 2018.

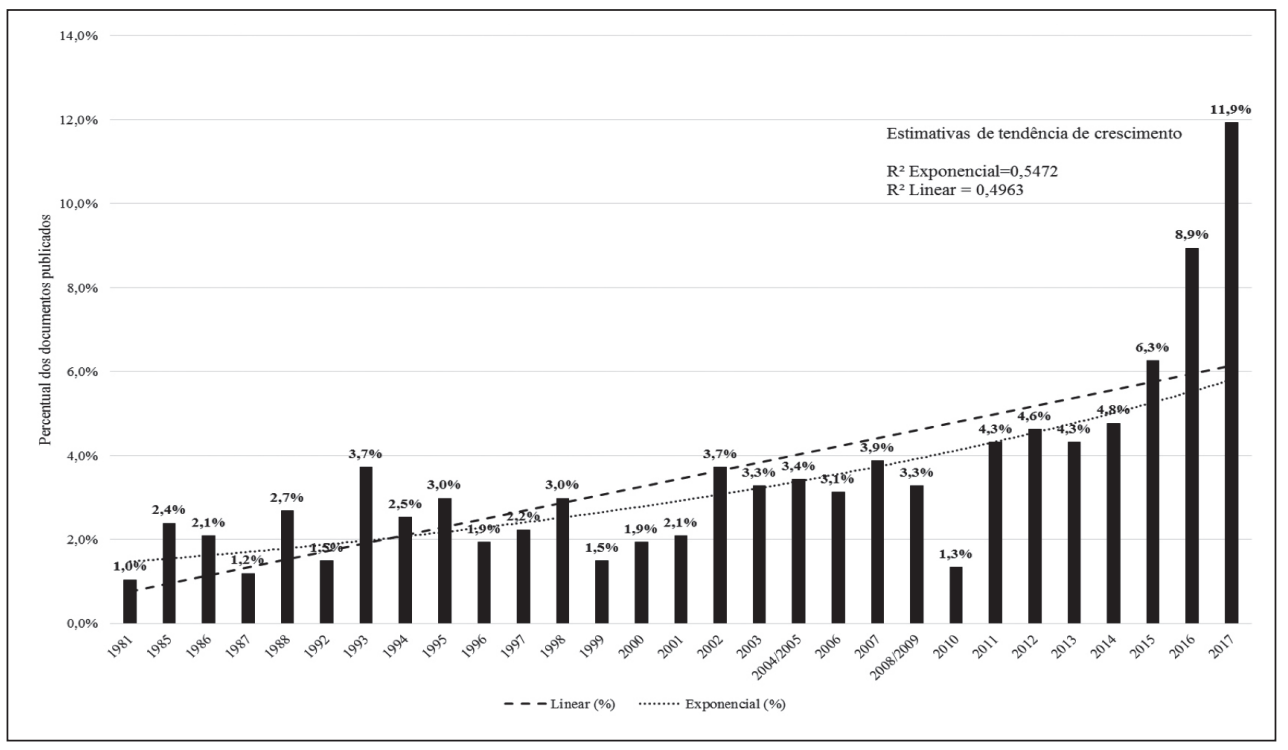


No que se refere ao número de publicação por autor, as dez autoras que mais publicaram na RBE estavam vinculadas à EEUFBA. As autoras com mais de dez artigos publicados na revista são: Josicelia Dumet Fernandes, Silvia Lucia Ferreira, Regina Lucia Mendonça Lopes, Maura Maria Guimaraes de Almeida e Enilda Rosendo do Nascimento.

Para identificar as temáticas abordadas, utilizaram-se descritores/palavras-chaves contidos nos artigos, de modo que foram identificados 913 termos dentre os 3287 apontados pelos autores. O exemplo de vulnerabilidade em saúde, usuários de drogas, úlcera cutânea, traqueostomia, revascularização miocárdica, entre outros. A nuvem de palavras, apresentada na Figura 3, aponta as temáticas tratadas nos artigos segundo os descritores. A centralidade do termo enfermagem como temática, está circundada pelas fases da vida humana (nascimento, infância, adolescer, gestação, fase adulta, idoso). Os agravos de maior prevalência atendidos nos serviços de saúde, tipologias de serviços de saúde, espaços de atuação (atenção primária e hospitalar) e enfermeiras(os) aparecem na zona intermediária da nuvem de palavras. $\mathrm{Na}$ periferia aparecem assuntos relacionados à educação, pesquisa e agravos reemergentes e negligenciados (HIV e hanseníase).

Tabela 1. Distribuição dos tipos de documentos publicados na RBE de 1981 a 2017. Salvador - Bahia 2018.

\begin{tabular}{lrc}
\hline Tipo de Publicaçáo & N & \% \\
\hline Artigos Originais & 432 & 64,38 \\
Artigos de Revisão & 88 & 13,11 \\
Relatos de Experiência & 44 & 6,56 \\
Reflexão & 35 & 5,22 \\
Estudos de caso & 17 & 2,53 \\
Não Informado & 20 & 2,98 \\
Resenhas & 19 & 2,83 \\
Resumos & 12 & 1,79 \\
Conferência & 1 & 0,15 \\
Ensaios & 2 & 0,30 \\
Memorial & 1 & 0,15 \\
\hline Total & 671 & 100,00 \\
\hline
\end{tabular}

Tabela 2. Distribuição das metodologias apontadas pelos autores nos artigos publicados na RBE de 1981 a 2017 . Salvador - Bahia 2018.

\begin{tabular}{lcc}
\hline Metodologia & Frequência & Porcentagem \\
\hline Qualitativa & 368 & $55,0 \%$ \\
Quantitativa & 136 & $20,3 \%$ \\
Nao informado & 93 & $13,6 \%$ \\
Quanti-qualitativo & 44 & $6,6 \%$ \\
Descritivo & 21 & $3,2 \%$ \\
Estudo bibliografico & 9 & $1,3 \%$ \\
\hline Total & 671 & $100,00 \%$ \\
\hline
\end{tabular}


Tabela 3. Procedência dos autores segundo região e estado da instituição de ensino, 1981-2017. Salvador - Bahia, 2018 $(\mathrm{N}=1441)$.

\begin{tabular}{|c|c|c|c|c|c|}
\hline Regiáo & $\mathbf{n}$ & $\%$ & Estado & $\mathbf{n}$ & $\%$ \\
\hline \multirow[t]{4}{*}{ Centro-oeste } & 36 & 2,5 & Distrito Federal & 13 & 0,9 \\
\hline & & & Goiás & 7 & 0,5 \\
\hline & & & Mato Grosso & 14 & 1,0 \\
\hline & & & Mato Grosso do Sul & 2 & 0,1 \\
\hline \multirow[t]{9}{*}{ Nordeste } & 887 & 61,6 & Alagoas & 1 & 0,1 \\
\hline & & & Bahia & 692 & 48,0 \\
\hline & & & Ceará & 78 & 5,4 \\
\hline & & & Maranhão & 10 & 0,7 \\
\hline & & & Paraíba & 32 & 2,2 \\
\hline & & & Pernambuco & 7 & 0,5 \\
\hline & & & Piauí & 21 & 1,5 \\
\hline & & & Rio Grande do Norte & 42 & 2,9 \\
\hline & & & Sergipe & 4 & 0,3 \\
\hline \multirow[t]{4}{*}{ Norte } & 23 & 1,6 & Acre & 9 & 0,6 \\
\hline & & & Tocantins & 1 & 0,1 \\
\hline & & & Amazonas & 3 & 0,2 \\
\hline & & & Pará & 10 & 0,7 \\
\hline \multirow[t]{4}{*}{ Sudeste } & 297 & 20,6 & Minas Gerais & 99 & 6,9 \\
\hline & & & Espirito Santo & 1 & 0,1 \\
\hline & & & Rio de Janeiro & 74 & 5,1 \\
\hline & & & São Paulo & 123 & 8,5 \\
\hline \multirow[t]{3}{*}{ Sul } & 156 & 10,8 & Paraná & 35 & 2,4 \\
\hline & & & Rio Grande do Sul & 59 & 4,1 \\
\hline & & & Santa Catarina & 62 & 4,3 \\
\hline $\begin{array}{l}\text { Não Informado/ } \\
\text { outros países }\end{array}$ & 42 & 2,9 & Não Informado & 42 & 2,9 \\
\hline Total & 1441 & 100,0 & Total & 1441 & 100,0 \\
\hline
\end{tabular}

Figura 3. Nuvem de palavras elaborada a partir da frequência de ocorrência dos descritores/palavras-chave indicadas nos artigos 1981-2017. Salvador, Bahia, 2018 (N=3287).

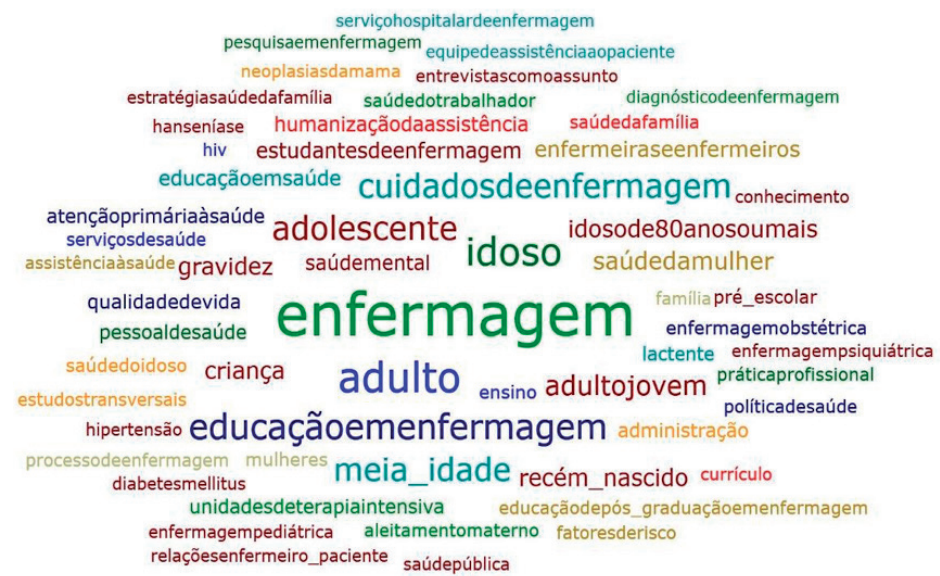




\section{DISCUSSÃO}

A pesquisa histórica remonta realidades vividas e fornece subsídios para elucidar o contexto vivido e compreender os significados desse contexto $^{(3)}$. O conjunto de documentos selecionados que versavam sobre a Revista Baiana de Enfermagem direcionou a reconstrução da sua história, as vivências perpassadas em sua trajetória de implantação, reestruturação e consolidação de sua imagem, transformando-a em um espaço de reflexão e aprofundamento do conhecimento científico.

Evidencia-se nalinha do tempo da RBE(Figura 1) que ela nasce como reflexo de uma grande conquista para a enfermagem da EEUFBA: o aniversário de 35 da escola. Objetivava, desde já, ser referência na produção científica para os profissionais da área no estado e em toda regiấo nordeste, trajetória alavancada pela implantação dos cursos de pósgraduação stricto sensu e consequentemente um maior número de pesquisadores ativos.

Em 1983, a publicação da Portaria 3/83 trata da estruturação da equipe editorial da RBE. Os artigos do primeiro fascículo versavam sobre temáticas como a saúde mental, a enfermagem médico-cirúrgica, a saúde da mulher, a saúde pública e a administração de enfermagem, denotando a característica do periódico em possibilitar espaço para múltiplas perspectivas de atuação da profissão. Entretanto, nos anos seguintes não houve periodicidade do periódico, dada a dificuldade de captação de recursos para o financiamento do processo editorial ${ }^{(8)}$.

Este fato comunga com a realidade vivenciada pelo Brasil à época. Na década de 80 se estabelecia o processo de redemocratização no país, concomitante a uma grave crise financeira e, nesse contexto, as políticas econômicas contingenciaram recursos em áreas como saúde, educação, entre outras e impuseram ao Ministério da Educação e Cultura sucessivos cortes orçamentários, repercutindo na universidade. Esse cenário impactou na periodicidade da RBE, atrasando a publicação do segundo volume, que só ocorreu quatro anos após, em 1985.

A repercussão financeira sobre a periodicidade da revista também foi experimentada por periódicos editados por outras universidades e pela Revista Brasileira de Enfermagem (REBEn), a qual passou por crises semelhantes na década de 1940 e dificuldade em manter a periodicidade, também envolta em circunstâncias externas ${ }^{(1)}$.

Outra revista de circulação nacional que enfrentou obstáculos para manutenção ao longo da sua trajetória foi a Revista Gaúcha de Enfermagem, que contou com o esforço do próprio corpo docente institucional para mantê-la ativa ${ }^{(9)}$.

Assim, destacamos ainda que, como suas antecessoras, a história da $\mathrm{RBE}$ se aproximou dos desafios de outros periódicos de enfermagem no Brasil à época ${ }^{(10)}$ : a Revista da Escola de Enfermagem da Universidade de São Paulo, uma das pioneiras, criada em 1967, com caráter semestral, iniciou sua publicação quadrimestral apenas em 1975 e, a partir de 1988, ganhou formato trimestral, além da publicação de números especiais, devido à dificuldades em manter a periodicidade ${ }^{(11)}$.

Aliado à necessidade em atender aos desafios impostos à ciência brasileira moderna e à exigências da comunidade científica, a RBE alcança, em 1986, a indexação na BDENF e LILACS. No ano 2000 foi mais longe ao adotar a plataforma eletrônica para avançar na qualidade e acessibilidade do processo editorial e, nesse cenário de superação, obtém qualificação B2 da Capes em 2012.

Em 2015 atinge os critérios para indexação nas bases REVENF, PROQUEST e SCOPUS, consolidando seu crescimento, sua internacionalização, com acesso universal e gratuito, vinculada à Biblioteca Virtual em Saúde - Enfermagem (BVS-ENF). Os parâmetros para a internacionalização, a necessidade da publicação inglês/português, plataforma para acesso on-line, diminuição do tempo entre submissão e publicação, aumento de consultores/pareceristas e publicação de autores internacionais, passam a ser desafios postos para o século $\mathrm{XXI}^{(9)}$.

Além de atender ao movimento de internacionalização, o acesso aberto ao conteúdo da revista implicou na mudança sobre o modo de arrecadação de recursos. O financiamento do processo editorial passou a ser parcialmente custeado pelo Programa de Pós-Graduação em Enfermagem e pelos autores, mas sem cobrança de taxa de publicação. Houve transformaçôes na apresentação gráfica, nos critérios de normalização, critérios de aceitação de artigos, na política editorial e na composição dos Conselhos Editoriais e de Consultores Ad-Hoc.

Esse movimento de livre acesso favorece a redução de custos e prazo na publicação dos artigos, "o que 
alterou a periodicidade dos fascículos e contribuiu para a pontualidade das ediçóes”, proporcionando agilidade no processo editorial. Atualmente a RBE possui publicação em fluxo contínuo, com volume anual de 80 artigos originais, além das revisóes e editoriais $^{(12)}$.

A internacionalização da pesquisa trata-se de um desafio não só da RBE, mas de todos os periódicos brasileiros, visto que, desde 2014, a CAPES vem gerando discussóes e fomentando editais de financiamento para auxiliar na profissionalização e internacionalização da pesquisa brasileira, a fim de expandir o processo de divulgação com abrangência internacional, visando maior exposição e impacto global das pesquisas publicadas nas revistas nacionais ${ }^{(13)}$.

No entanto, a internacionalização não depende apenas de sistemas automatizados, mas também do aprimoramento dos processos editoriais, de autores e de avaliadores. Assim, avanços relevantes devem ser empreendidos para que a comunidade entenda que autores e avaliadores possuem responsabilidade sobre o aprimoramento ${ }^{(14)}$.

Ao longo da trajetória da RBE observou-se um crescimento linear do número de artigos publicados (Figura 2), ainda que em alguns períodos essa tendência tenha apresentado uma diminuição. Um dado importante é que a produçáo científica de 2013-2017 alcançou o equivalente a 46\% superior à primeira década do século XXI, demonstrando a expansão das publicações em enfermagem na RBE.

Segundo estudo sobre a produção científica da área de enfermagem aponta que entre 20042006 foram publicados 3563 artigos em 373 periódicos, com aumento de quase dois mil artigos e mais de 200 periódicos no período de 2007 a 2009. A maioria desses artigos $(78,2 \%)$ tiveram suas publicações em periódicos com Qualis B2 ou superior, sendo que os periódicos B2 representaram $19 \%$. Dados recentes mostram que esses números encontram-se ainda em expansão ${ }^{(15)}$.

No entanto, se observa uma mudança na frequência dos tipos de documentos (Tabela 1), e um incremento do quantitativo de artigos originais, refletindo as diretrizes de envio de manuscrito da revista. Observa-se um decréscimo no número de artigos tipo reflexão, resenhas e cartas, havendo variaçóes ano a ano, assim como repercussóes no processo de modernização do cenário editorial e nas exigências das bases indexadoras, onde a contribuição científica, relevância, originalidade e inovação são os aspectos mais valorizados por editores e revisores ${ }^{(16)}$.

Quanto às metodologias descritas pelos autores (Tabela 2), os dados corroboram com outro estudo sobre a tendência no desenvolvimento de pesquisas de abordagem qualitativa na área da enfermagem, especialmente os estudos de natureza fenomenológica, etnográfica, entre outras, na busca em obter as respostas dos complexos processos de construção da subjetividade do ser humano e do contexto organizacional ${ }^{(17)}$.

Evidencia-se uma endogenia local e regional (Tabela 3), fragilidade a ser superada pela revista. Contudo esta situação esteve condicionada muitas vezes à necessidade de manutenção da regularidade de publicação do periódico, onde os editores estimulavam os autores ou estes produziam pesquisa direcionada para publicação. Mas, com o processo de modernização, a recente indexação em bases de dados nacionais e internacionais retrata o aumento do consumo e da submissão de artigos procedentes de outros espaços geográficos.

Por outro lado a RBE cumpriu um importante papel social na divulgaçáo da produção do nordeste, visto o aumento dos cursos de doutorado no Brasil a partir de 2009, chegando a 34 programas em 2014 (aumento de $127 \%$ no período). Contudo, ainda persiste a concentraçáo de cursos de doutorado na regiấo Sudeste $(50 \%)$ e Sul $(21,9 \%)$. Na região Nordeste está concentrado $21 \%$ dos cursos e apenas 6,2\% no Centro Oeste, com inexistência na região norte até $2014^{(15)}$.

A procedência dos autores aponta para vínculo com estados que estão associados a maior quantitativo e antiguidade de programas de pós-graduação e, por conseguinte, produção acadêmica $^{(15)}$. No que concerne os autores que produziram com maior regularidade na RBE, são docentes que se destacam por uma produção contínua não só na $\mathrm{RBE}$, mas em periódicos de circulação nacional e internacional.

Nesse caminho a RBE definiu, a partir de 2018, a publicação final dos artigos bilíngue (português e inglês) e a modalidade de publicação em fluxo contínuo (Rolling Pass). Esse novo modelo visa agilizar o acesso e divulgaçáo dos artigos aprovados, visto que a publicação do manuscrito não precisa aguardar o fechamento do próximo número a ser publicado. Assim, os artigos publicados a partir de 2018 não contarão mais com um número de 
publicação, apenas com o volume, ou seja, não se terá mais fascículos.

A RBE em sua trajetória centralizou seu eixo temático nas áreas da enfermagem abarcando desde temas relacionados à prática clínica, identidade profissional, processo de trabalho, educação e pesquisa até agravos de maior prevalência atendidos nos serviços de saúde. No entanto, entende a necessidade de ampliar seu escopo temático de discussão para além da área de enfermagem, buscando outras áreas da saúde que estabeleçam interlocução durante o processo de produção do conhecimento, especialmente as áreas sociais e humanas, como a psicologia social e a sociologia, atendendo a multidimensionalidade do saber.

Outra mudança que também poderá causar impacto na ampliação do escopo temático é a mudança dos cursos de pós-graduação stricto sensu da Escola de Enfermagem da UFBA de pós-graduação específica em enfermagem para aárea multidisciplinar, impulsionando a mudança da política editorial em ampliar os limites da produção intelectual, seguindo as tendências contemporâneas de integração e complementaridade de conhecimentos.

Como desafios destaca-se a necessidade de alcançar novas bases de indexação internacional, agregar publicações não só na área da enfermagem, mas também de outras áreas da saúde, além de outras áreas com as quais a enfermagem estabelece interlocução durante o processo de produção do conhecimento, especialmente as áreas sociais e humanas, como a psicologia social e a sociologia.

\section{CONCLUSÃO}

O estudo descreveu a trajetória histórica da Revista Baiana de Enfermagem, construindo uma linha do tempo que abarca os marcos históricos de implantação, constituição e consolidação da revista, como veículo de divulgação da produção científica em enfermagem. A RBE enfrentou dificuldades para manter sua periodicidade, com mudanças no processo editorial, elevaçáo do conceito da CAPES e alcance de critérios para associar-se à base de dados nacionais e internacionais, além da garantia de acessibilidade gratuita.

Nos dados bibliométricos podemos destacar a curva de crescimento linear da revista, os principais tipos de documentos publicados e sua dispersão pelos anos, visibilizando um maior número de artigo de reflexão no período da década de 80 e um crescimento dos artigos originais na década 2000. Foi possível identificarmos os principais autores e suas afiliaçōes, o que demarcou a característica da endogamia em alguns momentos da sua história. Ainda foi possível observar os percursos em construção para a ampliação da temática da revista, buscando áreas para além do campo da enfermagem e que, também, corroboram no processo de produção científica.

Conclui-se que a RBE contribuiu para democratização de pesquisas e fontes documentais, articulando pesquisadores de diferentes partes do país e do mundo, marcando principalmente a especificidade da produção histórica na região nordeste do Brasil e vislumbrando novos horizontes e possibilidades de como alcançar padróes internacionais de qualidade para galgar indexação em diversas bases de dados.

A escassez de registros históricos sobre a criação e evolução da revista apresentou-se como uma limitação do estudo. Entretanto, a análise das fontes e o uso de técnicas bibliométricas permitiram completar uma lacuna e subsidiar a análise dos aspectos sobre a história da produção científica em enfermagem no nordeste e Brasil, contribuindo para os estudos do domínio da História da Enfermagem.

\section{REFERÊNCIAS}

1. Carvalho AC. Associação Brasileira de Enfermagem-1926/1976: documentário. Rev bras enferm. 2002; 55(3): 249-263. doi: http://dx.doi. org/10.1590/S0034-71672002000300003
2. Fernandes JD. Significado da Reativação da Revista da EEUFBA. Editorial. Rev baiana enferm. 1985; 1(1): 1-2.

3. Borenstein MS, Padilha MI. Enfermagem em Santa Catarina: recortes de uma história. (1900-2011). Florianópolis: Editora Secco; 2011. 277 p.

4. Belloto, HL. Arquivos permanentes: tratamento 
documental. $4^{\mathrm{a}}$ ed. Rio de Janeiro: Fgv; 2006. p. 227-247.

5. Prais JLS, Rosa VF. Nuvem de palavras e mapa conceitual: estratégias e recursos tecnológicos na prática pedagógica. Nuances: estudos sobre Educação. 2017; 28(1): 201-219. Disponível em: http://revista.fct.unesp.br/index.php/Nuances/ article/view/4833/pdf_1

6. Fernandes JD. O fortalecimento da Atividades Acadêmicas da escola de Enfermagem da Universidade Federal da Bahia 1979 a 1989. In: Fernandes JD, coordenadora. Memorial Escola de Enfermagem: 1946-1996. Salvador: Universidade Federal da Bahia; 2001. p. 163-209.

7. Ata da reunião extraordinária do Conselho Departamental da Escola de Enfermagem em 08 de maio de 1995. Rev baiana enferm. 1995.

8. Paiva MS, Coelho EAC, Nascimento ER, Melo CMM, Fernandes JD, Santos NA. Perfil profissional de egressas da Área de Gerenciamento do Programa de Pós-Graduação em Enfermagem da UFBA. Rev esc enferm USP. 2011; 45(spe): 1558-65. doi: http://dx.doi.org/10.1590/S008062342011000700004

9. Pedro ENR. Revista Gaúcha de Enfermagem: 40 anos divulgando a produçáo de conhecimento. Rev Gaúcha Enferm. 2016; 37(1): e62661. doi: http:// dx.doi.org/10.1590/1983-1447.2016.01.62661.

10. Oliveira JF, Rodrigues GRS, Paiva, MS. Revista Baiana de Enfermagem: 35 anos de conquistas e desafios. Rev baiana enferm. 2016; 30(4): 1-3. doi:http://dx.doi.org/10.18471/rbe.v30i4.20535
11. Ito EE, Takahashi RT. Publicaçóes sobre ensino em enfermagem na Revista da Escola de Enfermagem da USP. Rev esc enferm USP. 2005; 39(4): 409416. doi: http://dx.doi.org/10.1590/S008062342005000400006

12. Avena MJ, Barbosa DA. Brazilian nursing journals: strengths, weaknesses and challenges. Rev Bras Enferm [Internet]. 2018; [citado 2018 ago 12]; 71(5): 2489-95. doi: http://dx.doi. org/10.1590/0034-7167-2017-0828

13. Trevizan MA, Mendes IACA. Pesquisa Histórica como necessidade na Enfermagem. Rev Gaúcha Enferm. 1985; 6(1): 27-34.

14. Nascimento ER, Lima LLG, Tyrrell MAR. O desenvolvimento da enfermagem e a inserção social das mulheres. Rev baiana enferm [Internet]. 2003. [citado 2016 ago 15]; 18(1/2): 11-8. Disponível em: https://portalseer.ufba.br/index.php/enfermagem/ article/view/3812/2832

15. Scochi CGS, Gelbcke FL, Ferreira MA, Lima MAS, Padilha KG, Padovani NA, Munari DB. Doutorado em Enfermagem no Brasil: formação em pesquisa e produçáo de teses. Rev Latino-Am Enfermagem. 2015; 23(3): 387-94. doi: http:// dx.doi.org/10.1590/0104-1169.0590.2564

16. Falaster C, Ferreira MP, Canela R. Motivos de rejeição dos artigos nos periódicos de administração. Organ Soc. 2016; 23(77): 285-306. doi: http:// dx.doi.org/10.1590/1984-9230776.

17. Medeiros M. Pesquisas de abordagem qualitativa. Rev Eletr Enf. 2012; 14(2): 224-5. doi: http:// dx.doi.org/10.5216/ree.v14i2.13628. 